Family Profile No. 2, 2021

\title{
Unintended Births: Variation across Social and Demographic Characteristics
}

Author: Karen Benjamin Guzzo

Disparities in unintended childbearing remain a public health concern (Healthy People 2030). Using the 2015-19 cycle of the National Survey of Family Growth, we examine sociodemographic variation in birth intendedness, looking at births occurring between 2014-2018 to women aged 15-49. Birth intendedness is based on a series of questions in which women are asked to characterize each birth as on time, mistimed (wanted but occurring earlier than desired), or unwanted (the respondent did not want any births at all, or any additional births). When births are reported as too early, women were then asked how much earlier than desired the birth occurred. We categorize mistimed births into two groups: slightly mistimed (less than two years earlier than desired) or seriously mistimed (two or more years too early). This profile is an update of FP-17-09 ${ }^{1}$ and the second in a series on unintended childbearing in the U.S.

\section{Birth Intendedness by Birth Order}

Overall, $69 \%$ of all recent births to women aged $15-49$ between 2014 and 2018 were intended; that is, they were reported as on time (not shown).

- The majority of births across all birth orders were on time, with the highest proportion of on-time births occurring among second births (75\%).

- Seriously mistimed births - those more than two years too early - were most common among first births (16\%).

- Slightly mistimed births - those two years too early or less - comprised a larger share of second and third or later births ( $10 \%$ for both) than first births (7\%).

- Third or later births were more often unwanted $(23 \%)$ than second $(10 \%)$ or first $(7 \%)$ births.

\section{Birth Intendedness by Union Status}

Figure 2: Variation in Intendedness by Union Status

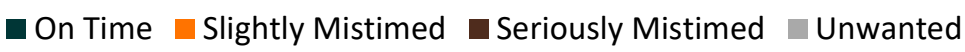

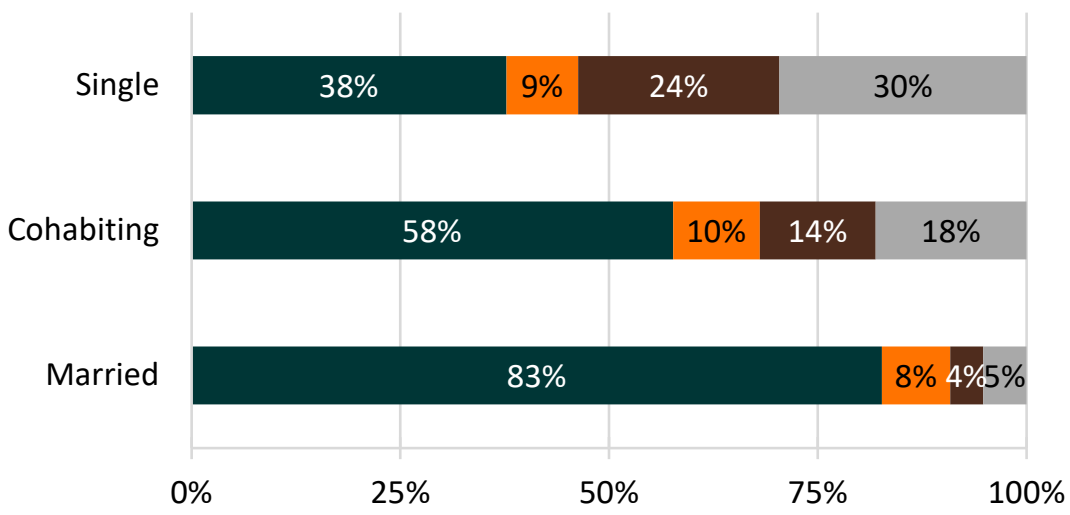

Figure 1. Variation in Intendedness by Birth Order

@ On Time $\backsim$ Slightly Mistimed $\square$ Seriously Mistimed $\square$ Unwanted

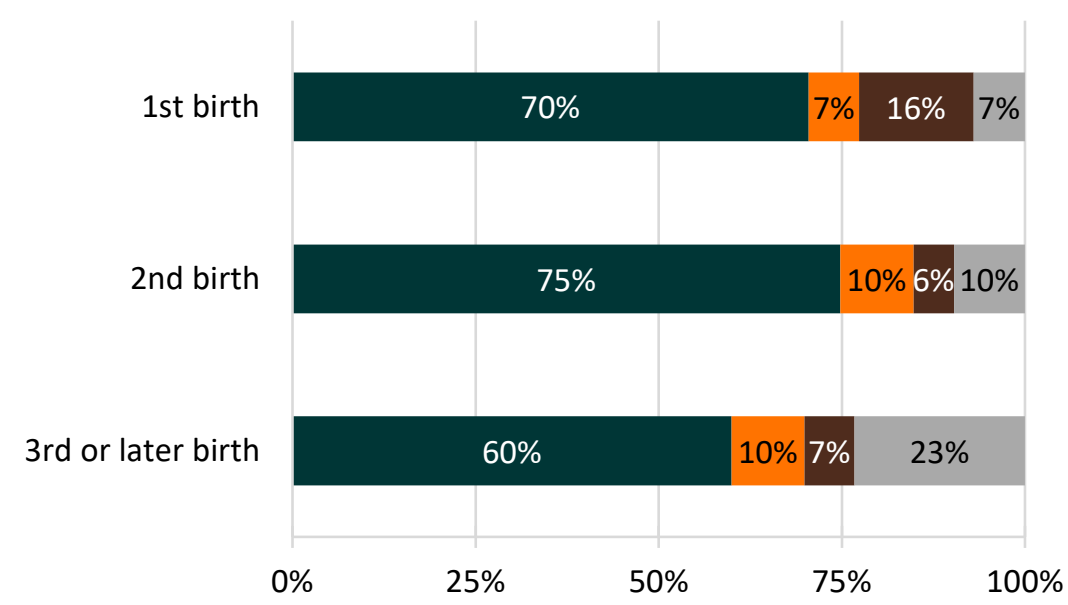

Source: NCFMR analyses of pregnancy data files from NSFG cycles 2015-17 and 2017-2019.

Source: NCFMR analyses of pregnancy data files from NSFG cycles 2015-17 and 2017-2019.

- A large majority (83\%) of marital births were on time compared to $58 \%$ of cohabiting births and $38 \%$ of single births.

- Mistimed births occurred more often among single (33\%) and cohabiting (24\%) women than married women (12\%).

o The share of recent births to single women that were seriously mistimed was six times higher than for married women.

- Nearly one in three (30\%) births to single women was unwanted, considerably higher than the $18 \%$ of such births to cohabiting women and $5 \%$ of such births to married women.

\footnotetext{
${ }^{1}$ The 2015-2019 cycle of the NSFG expanded its age range to 49 (up from age 45 in prior cycles) and released a slightly different set of variables on race-ethnicity. As such, the estimates in this profile are not directly comparable to profile FP-17-09.
} 
Birth Intendedness by Educational Attainment

There was a clear educational gradient to unintended fertility among recent births.

- Most recent births (84\%) to women with a college degree were on time compared to just over half (55\%) of births to women without a high school diploma.

- Just $3 \%$ of births to women with a college degree were seriously mistimed, with much higher percentages among women with less than a college degree (ranging from 10\%-17\%).

- Only $4 \%$ of births to women with a college degree were unwanted, while one in five of such births $(19 \%)$ to women without a high school degree was unwanted.

\section{Birth Intendedness by Race \& Ethnicity}

Figure 4: Variation in Intendedness by Race \& Ethnicity

-On Time $\square$ Slightly Mistimed $\square$ Seriously Mistimed $\square$ Unwanted

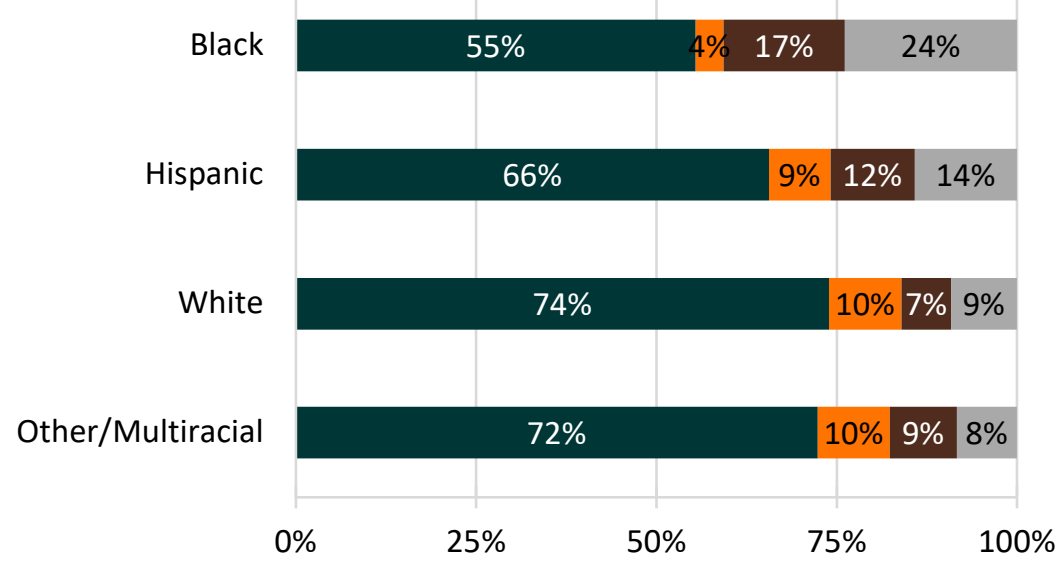

Source: NCFMR analyses of pregnancy data files from NSFG cycles 2015-17 and 2017-2019.
Figure 3: Variation in Intendedness by Educational Attainment On Time $\square$ Slightly Mistimed $\square$ Seriously Mistimed $\square$ Unwanted

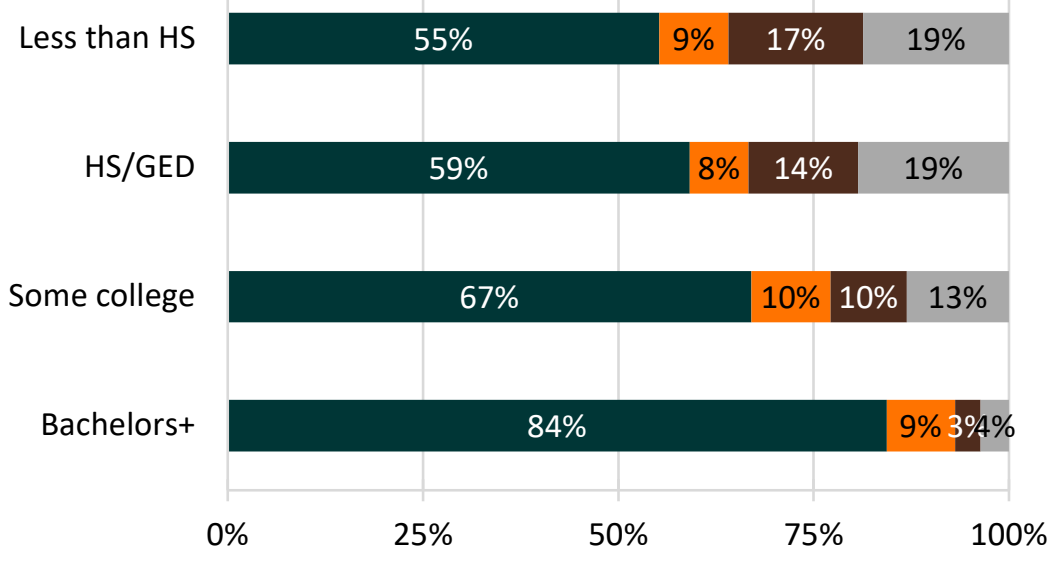

Source: NCFMR analyses of pregnancy data files from NSFG cycles 2015-17 and 2017-2019.

The majority of recent births were on time across racialethnic groups.

- The proportion of births that were on time ranged from $55 \%$ among Black women to $74 \%$ among White women.

- Mistimed births occurred most often among Hispanic and Black women (21\%) and least often among White women (17\%).

- Black women had the highest share of births characterized as unwanted (24\%) whereas births to multiracial and other-race women (8\%) were least often unwanted.

\section{Data Sources:}

National Center for Health Statistics (NCHS). 2015-17 and 2017-2019 National Survey of Family Growth Public-Use Data and Documentation. Hyattsville, MD: CDC National Center for Health Statistics. https://www.cdc.gov/nchs/nsfg/index.htm

\section{References:}

Healthy People 2030 (2021). Reduce the proportion of unintended pregnancies, FP-01. Washington, DC: U.S. Department of Health and Human Services, Office of Disease Prevention and Health Promotion. Healthy People 2030 | health.gov Accessed 1/7/21.

\section{Suggested Citation:}

Guzzo, K. B. (2021). Unintended births: Variation across social and demographic characteristics. Family Profiles, FP-21-02. Bowling Green, OH: National Center for Family \& Marriage Research. https://doi.org/10.25035/ncfmr/fp-21-02

BGSU. National Center for
B O w L I N G G R E E N S T A T E U N I V E R s I T Y
This project is supported with assistance from Bowling Green State University. From 2007 to 2013, support was
the U.S. Department of Health and Human Services, Office of the Assistant Secretary for Planning and Evaluation. The opinions and conclusions expressed herein are solely those
of the author(s) and should not be construed as representing the opinions or policy of any agency of the state or federal government.

